\title{
Linkage of Type 2 Diabetes on Chromosome 9p24 in Mexican Americans: Additional Evidence from the Veterans Administration Genetic Epidemiology Study (VAGES)
}

\author{
Vidya S. Farook ${ }^{a}$ Dawn K. Coletta ${ }^{b}$ Sobha Puppala ${ }^{a}$ Jennifer Schneider ${ }^{a}$ Geetha Chittoor ${ }^{a}$ \\ Shirley L. Huc Deidre A. Winnier ${ }^{d}$ Luke Norton ${ }^{d}$ Thomas D. Dyer ${ }^{a}$ Rector Arya ${ }^{f}$ \\ Shelley A. Cole ${ }^{a}$ Melanie Carless ${ }^{a}$ Harald H. Göring ${ }^{a}$ Laura Almasy $^{a}$ Michael C. Mahaney ${ }^{a}$ \\ Anthony G. Comuzzie ${ }^{a}$ Joanne E. Curran ${ }^{a}$ John Blangero ${ }^{a}$ Ravindranath Duggirala ${ }^{a}$ \\ Donna M. Lehman ${ }^{\mathrm{e}}$ Christopher P. Jenkinson ${ }^{\mathrm{a}, \mathrm{c}, \mathrm{d}}$ Ralph A. DeFronzo ${ }^{c, d}$ \\ aSouthwest Foundation for Biomedical Research, San Antonio, Tex., ${ }^{b}$ Center for Metabolic Biology, Arizona State

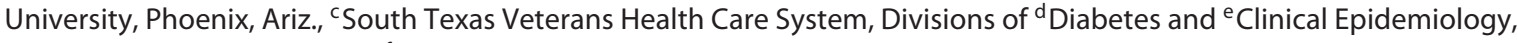 \\ Department of Medicine, and ${ }^{\mathrm{f}}$ Division of Endocrinology and Diabetes, Department of Pediatrics, The University of \\ Texas Health Science Center at San Antonio, San Antonio, Tex., USA
}

\section{Key Words}

Type 2 diabetes · Linkage · Chromosome 9p24 .

Mexican Americans · VAGES

\begin{abstract}
Objective: Type 2 diabetes (T2DM) is a complex metabolic disease and is more prevalent in certain ethnic groups such as the Mexican Americans. The goal of our study was to perform a genome-wide linkage (GWL) analysis to localize T2DM susceptibility loci in Mexican Americans. Methods: We used the phenotypic and genotypic data from 1,122 Mexican-American individuals (307 families) who participated in the Veterans Administration Genetic Epidemiology Study (VAGES). GWL analysis was performed using the variance components approach. Data from 2 additional Mexican-American family studies, the San Antonio Family Heart Study (SAFHS) and the San Antonio Family Diabetes/Gallbladder Study (SAFDGS), were combined with the VAGES data to test for improved linkage evidence. Results: After
\end{abstract}

adjusting for covariate effects, T2DM was found to be under significant genetic influences $\left(h^{2}=0.62, p=2.7 \times 10^{-6}\right)$. The strongest evidence for linkage of T2DM occurred between markers D9S1871 and D9S2169 on chromosome 9p24.2-p24.1 (LOD = 1.8). Given that we previously reported suggestive evidence for linkage of T2DM at this region also in SAFDGS, we found the significant and increased linkage evidence $\left(\mathrm{LOD}=4.3\right.$, empirical $p=1.0 \times 10^{-5}$, genome-wide $p=1.6 \times 10^{-3}$ ) for T2DM at the same chromosomal region, when we performed a GWL analysis of the VAGES data combined with the SAFHS and SAFDGS data. Conclusion: Significant T2DM linkage evidence was found on chromosome 9p24 in Mexican Americans. Importantly, the chromosomal region of interest in this study overlaps with several recent genome-wide association studies involving T2DM-related traits. Given its overlap with such findings and our own initial T2DM association findings in the 9p24 chromosomal region, high throughput sequencing of the linked chromosomal region could identify the potential causal T2DM genes.

\section{KARGER}

E-Mail karger@karger.com

www.karger.com/hhe
(C) 2013 S. Karger AG, Basel

0001-5652/13/0761-0036\$38.00/0
Prof. Ralph A. DeFronzo, MD

Division of Diabetes, Department of Medicine

The University of Texas Health Science Center at San Antonio

7703 Floyd Curl Drive, San Antonio, TX 78229-3900 (USA)

E-Mail albarado@uthscsa.edu 


\section{Introduction}

Type 2 diabetes (T2DM) is a complex metabolic disease, characterized by insulin resistance and impaired $\beta$-cell function [1-3]. T2DM continues to be a major global public health problem and a large economic burden. Approximately 24 million people in the United States are estimated to have diabetes, and about 48 million people are projected to have diabetes by the year 2050 if current demographic trends continue [4]. Also, the prevalence of T2DM is disturbingly high in US ethnic minorities such as the Mexican Americans [5]. Both genetic and environmental factors play important roles in the development of T2DM [1, 6-9]. There have been continued efforts to localize and characterize T2DM susceptibility genes using genome-wide linkage (GWL) and, most recently, genome-wide association approaches. Although linkage studies have identified various T2DM susceptibility loci [10], subsequent gene discovery successes from such efforts have been limited. In recent years, as an alternative gene localization tool, the genome-wide association study (GWAS) method has become a popular design with several notable successes in localizing several novel T2DM susceptibility genes/variants [11]. This approach is based on the common variant/common disease hypothesis, and generally uses data from large samples of unrelated cases and controls. So far, more than 60 T2DM susceptibility loci have been localized with genome-wide significance [12-16]. Of these loci, only the transcription factor 7-like 2 (TCF7L2) gene was localized as a follow-up to the previous report of linkage of T2DM to the $10 \mathrm{q}$ chromosomal region in an Icelandic population $[17,18]$, where we previously found evidence for linkage of T2DM in Mexican Americans [19].

GWASs have contributed greatly to the understanding of the genetic architecture of T2DM. However, for most cases, the identity of the causal genes and the functional relevance of the implicated genetic variants have yet to be established. As has been the case with various GWASs of other complex diseases, the genetic contribution of common variants identified by the GWASs to the overall susceptibility to T2DM is rather modest. These observations have led to thoughts of 'missing heritability' and 'synthetic associations', in turn highlighting the potential role of rare variants of large effect [20-22]. However, following Gibson [22], it is conceivable that both common and rare variants could be important contributors to complex disease risk. Although most of the T2DM GWASs have involved populations of European ancestry, their relevance to other ethnic groups, such as Mexican Americans, who are at a high T2DM risk, has been examined with attention, focused on issues such as allele frequency and linkage disequilibrium differences among diverse populations [23]. However, recently, the transferability of previous GWAS findings in multiethnic populations has been reported [24-26].

Therefore, the purpose of this study was to perform a GWL analysis to localize T2DM susceptibility loci in Mexican Americans residing in San Antonio, Texas, for potential subsequent efforts of fine-mapping for identifying the causal variants, both rare and common, which could be specific for the Mexican-American population. To meet our objective, first, we used data from the Veterans Administration Genetic Epidemiology Study (VAGES) and performed a GWL analysis using variance components linkage analytical techniques implemented in the program SOLAR [27]. Second, since we previously reported T2DM linkage signals from another MexicanAmerican family study in San Antonio, the San Antonio Family Diabetes/Gallbladder Study (SAFDGS) [19, 28], the present study has also combined the VAGES data with those from SAFDGS and a second Mexican-American family study in San Antonio, the San Antonio Family Heart Study (SAFHS), to perform a GWL analysis for examining whether the use of the combined data would yield improved evidence for linkage at any of the genetic locations found to be linked with T2DM in our SAFDGS and/or VAGES data sets.

\section{Research Design and Methods}

The Veterans Administration Genetic Epidemiology Study

The demographic, genotypic, and phenotypic data were collected from Mexican-American individuals who had been enrolled in VAGES. The study procedures have been described elsewhere [29]. In this study, we used data from 1,122 participants from 307 Mexican-American families for whom the diabetic status was known (table 1). The VAGES families were ascertained based on at least 2 siblings and 1 parent affected with T2DM. These 1,122 study participants generated a total of 1,950 relative pairs with varying degrees of genetic relationships. Of these 1,950 pairs, 350 were unaffected-unaffected pairs, 847 were unaffected-affected pairs, and 753 were affected-affected pairs (table 2 ). The study protocol was approved by the Institutional Review Board of the University of Texas Health Science Center at San Antonio, and written informed consent was obtained from all subjects.

\section{Phenotypic Data}

The phenotypic data for various metabolic and anthropometric traits, including information on medical history, were collected for the study participants [29]. In addition to the fasting plasma glucose concentration, plasma glucose levels were 
Table 1. Clinical characteristics of the individuals from VAGES, SAFDGS, SAFHS, and the combined data

\begin{tabular}{lcccc}
\hline & VAGES & SAFDGS & SAFHS & Combined data \\
\hline Sample size, $\mathrm{n}$ & 1,122 & 557 & 1,407 & 3,086 \\
Age, years & $49 \pm 13$ & $42 \pm 17$ & $39 \pm 17$ & $43 \pm 16^{*}$ \\
Females, \% & 65 & 59 & 60 & $62^{*}$ \\
T2DM,$\%$ & 65 & 26 & 16 & $36^{* *}$ \\
Age at T2DM onset, years & $44 \pm 12$ & $49 \pm 14$ & $48 \pm 15$ & $45 \pm 13^{* *}$ \\
BMI & $33.2 \pm 7.8$ & $30.1 \pm 6.6$ & $29.3 \pm 6.6$ & $30.8 \pm 7.3^{* *}$ \\
Waist circumference, mm & $1,036.2 \pm 169.6$ & $975.2 \pm 174.7$ & $948.0 \pm 171.7$ & $984.5 \pm 176.0^{* *}$ \\
\hline \multirow{2}{*}{ a Diagnosed according to the WHO criteria [30]. } & & \\
${ }^{*}$ p $<0.01 ; *$ p $<0.0001$. p value was not corrected for non-independence. & \\
\hline
\end{tabular}

Table 2. Number and types of relative pairs generated from 1,122 VAGES participants distributed across 307 families in the present study

\begin{tabular}{llccr}
\hline Type of relative pairs & $\begin{array}{l}\text { Relationship } \\
\text { coefficient }^{\mathrm{a}}\end{array}$ & $\begin{array}{l}\text { Unaffected- } \\
\text { unaffected pairs, } \mathrm{n}\end{array}$ & $\begin{array}{l}\text { Unaffected- } \\
\text { affected pairs, } \mathrm{n}\end{array}$ & $\begin{array}{l}\text { Affected- } \\
\text { affected pairs, } \mathrm{n}\end{array}$ \\
\hline Parent-offspring & 0.5000 & 52 & 194 & 200 \\
Siblings & 0.5000 & 203 & 489 & 484 \\
Grandparent-grandchild & 0.2500 & 3 & 13 & 2 \\
Avuncular & 0.2500 & 62 & 111 & 34 \\
Half-siblings & 0.2500 & 10 & 25 & 11 \\
Third degree & 0.1250 & 20 & 1 & - \\
Fourth degree & 0.0625 & - & 847 & 753 \\
\hline Total & & 350 & & 14 \\
\hline
\end{tabular}

a The relationship coefficient is $2 \times$ the coefficient of kinship of 2 individuals.

measured during a 2-hour oral (75 g) glucose tolerance test. The subjects were classified as having T2DM, if they had a fasting glucose concentration $\geq 126 \mathrm{mg} / \mathrm{dl}$ and/or a glucose level after $2 \mathrm{~h}$ of $\geq 200 \mathrm{mg} / \mathrm{dl}$ according to the 1999 criteria of the World Health Organization [30]. Participants who did not meet these criteria, but reported to be under treatment with either oral antidiabetic agents or insulin, and those who gave a history of diabetes were also considered to have T2DM. Anthropometric data (i.e., height, weight, and waist circumference) were collected using standardized procedures. The body mass index (BMI) was calculated as weight in kilograms divided by the square of height in meters $\left(\mathrm{kg} / \mathrm{m}^{2}\right)$. For the analyses, the BMI was log transformed to provide an approximately normal distribution.

\section{Genotypic Data}

The Center for Inherited Disease Research (CIDR) performed an approximately 10-cM genome scan (i.e., 385 highly polymorphic autosomal STR markers) using the DNA samples from the VAGES participants [29]. The genetic map obtained from these data was used to localize T2DM susceptibility loci.
Briefly, the program PREST was used to resolve pedigree discrepancies. The programs PRESWALK and SimWalk2, as implemented in PEDSYS, were used to clean the genotype data of Mendelian inconsistencies and spurious double recombinants which may inflate map distances. Multipoint identical-by-descent matrices were estimated using Markov chain Monte Carlo methods implemented in the program Loki using SOLAR, as described previously [29]. To facilitate a comparison with other studies, the locations of our linkage findings were placed on the Marshfield genetic map.

\section{Statistical Analysis}

A variance components approach was used to evaluate the genetics of T2DM [31]. In a simple model, variances or covariances between relatives as a function of the genetic relationships can be specified, and the proportion of phenotypic variance that is attributed to additive genetic effects (i.e., heritability: $h^{2}$ ) can be estimated from the components of variance. We used an extension of the variance components method to a threshold model to test for linkage between genetic markers and the discrete trait T2DM [32]. 
Table 3. Genetic locations linked to T2DM with LOD scores $\geq 1.2$ based on multipoint linkage analyses of VAGES and combined data sets

\begin{tabular}{lccll}
\hline Marker region & $\begin{array}{l}\text { Distance from } \\
\text { p-ter, cM }\end{array}$ & Chromosomal location & \multicolumn{2}{l}{ Maximum LOD } \\
\cline { 4 - 5 } & & & VAGES & combined data \\
\hline D5S807 & 19 & $5 \mathrm{p} 15.31$ & - & 1.2 \\
D5S2494 & 59 & $5 \mathrm{p} 13.1$ & - & 1.7 \\
D5S629-D5S424 & $77-82$ & $5 \mathrm{q} 13.1-\mathrm{q} 13.3$ & - & 1.2 \\
D9S1779-D9S2169 & $0-14^{\mathrm{a}}$ & $9 \mathrm{p} 24.3-\mathrm{p} 24.1$ & 1.8 & 4.3 \\
D11S1999-D11S1981 & $17-21$ & $11 \mathrm{p} 15.3-\mathrm{p} 15.1$ & 1.5 & $(1.0)^{\mathrm{b}}$ \\
D21S1254-D21S1440 & $31-37$ & $21 \mathrm{q} 22.11-\mathrm{q} 22.13$ & - & 2.0
\end{tabular}

${ }^{\mathrm{a}}$ Combined data $=$ D9S1779-D9S1871 $(0-8 \mathrm{cM})$, and VAGES = D9S1871-D9S2169 $(8-14 \mathrm{cM}){ }^{\mathrm{b}}$ shown for the purpose of comparison with the VAGES finding.

Fig. 1. Findings from a multipoint linkage analysis of T2DM in the combined data. Genetic locations with potential evidence (LOD $\geq 1.2$ ) for T2DM linkage have a LOD scale next to them. The 11p chromosome finding is associated with a LOD score of 1.0 , and shown for the purpose of discussion.

Linkage of T2DM on Chromosome 9p24 in Mexican Americans

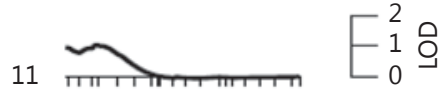

10
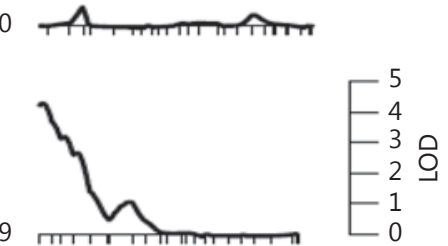

8

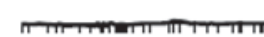

7

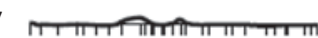

6

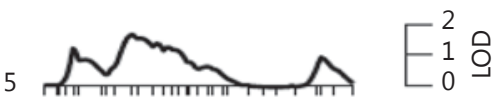

4
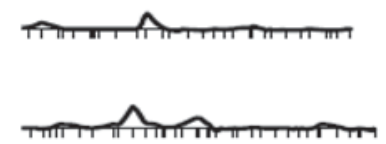

2

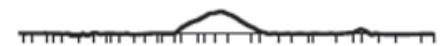

1

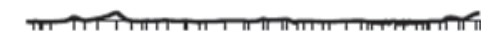

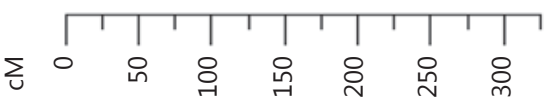

$22 \pi \pi m \pi n$

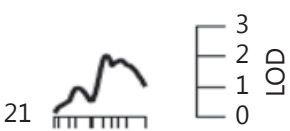

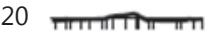

19

18

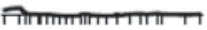

16

15

14

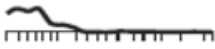

12

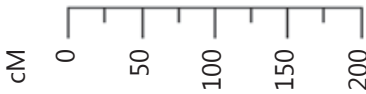


The variance components (i.e., heritability attributed to the susceptibility locus and heritability attributed to the residual additive genetic effects) and covariates for T2DM (e.g., age and sex) were estimated simultaneously in likelihood terms. A hypothesis testing of no linkage versus linkage was performed using the likelihood ratio test. Twice the difference in the ln likelihoods of these models yields a test statistic that is asymptotically distributed as $1 / 2: 1 / 2$ mixture of $\chi^{2}{ }_{1}$ and a point mass at 0 , denoted by $\chi_{0}^{2}$, where the degree of freedom (d.f.) is equal to the difference in the number of parameters estimated between the 2 competing models. LOD scores were obtained by converting the ln likelihood values into values of $\log$ to the base 10 . A LOD score of $\geq 3.0$ was considered as significant evidence in support of linkage. For the purpose of discussion, LOD scores $\geq 1.2$ were considered as evidence for potential linkage. Given the VAGES family ascertainment scheme, all genetic analyses including the estimation of heritability were performed by correcting for the ascertainment, as described previously [29]. The program SOLAR was used to perform the statistical, genetic, analytical procedures described above [31].

\section{Combined Data from VAGES, SAFHS, and SAFDGS for}

Linkage Analysis

Since VAGES, SAFHS, and SAFDGS are part of our ongoing San Antonio Family Birth Weight Study, the combined genetic maps, generated based on marker data from these 3 family studies, were used for this study [33]. For consistency with VAGES, the baseline phenotypic data from SAFHS and SAFDGS were used (table 1). SAFHS's and SAFDGS's study procedures have been described previously $[19,28,34,35]$. Briefly, the phenotypic data from 1,407 SAFHS participants from 42 large families and from 557 SAFDGS participants from 31 large families were utilized for the present study (table 1). T2DM and other phenotypic data were obtained using methods similar to the procedures in VAGES. All genetic analyses were performed using methods described previously. For the combined linkage analysis, 2 dummy variables were generated as additional covariates to account for the study effects. To verify our major T2DM linkage finding on chromosome 9p24, we performed a simulation analysis to determine the empirical $p$ value, using information obtained from 100,000 replicates. In addition, to address the issue of multiple testing, we estimated the genome-wide $\mathrm{p}$ value for the strongest T2DM linkage finding, following the method of Feingold et al. [36].

Preliminary Association Analysis of the T2DM-Linked Region on Chromosome 9p24

We screened for the potential common genetic variants influencing T2DM in the 1.5-LOD support interval using data from 2 (i.e., SAFHS and SAFDGS) of the 3 studies used for our linkage analysis (table 1). The 1.5-LOD support interval refers to the critical chromosomal region surrounding the linkage peak with an approximately $95 \%$ probability of containing the susceptibility locus [37]. We used our existing genome-wide genotypic data obtained from SAFHS and SAFDGS to select 5,329 single nucleotide polymorphisms (SNPs) representing the T2DM-linked region for the association analysis [38]. In addition, we also carried out similar analyses for fasting glucose and insulin data related to nondiabetic individuals only. The details of the genome-wide genotypic data involving approximately 950,000 SNPs, which were generated using several versions of Illumina's BeadChip microarrays and the Illumina Infinium protocol and processed using standard quality control procedures, were previously reported [38]. We used an additive measured genotype approach within the variance components framework to conduct an association analysis as implemented in the program SOLAR.

\section{Results}

The study-specific clinical characteristics of the participants are reported in table 1 . The VAGES data analyses involved information from 1,122 individuals (females: $65 \%$, mean age: 49 years, T2DM: $65 \%$, and mean BMI: 33 ), and the combined data analyses were based on information from 3,086 individuals (females: 62\%, mean age: 43 years, T2DM: $36 \%$, and mean BMI: 31 ). Initially, the heritability $\left(\mathrm{h}^{2} \pm \mathrm{SE}\right)$ of T2DM in the VAGES data was determined to be $0.62 \pm 0.16$ after adjusting for the significant $(p \leq 0.05)$ covariate effects of age, sex, age ${ }^{2}$ age $^{2}$ $\times$ sex, and ln BMI, which was highly statistically significant $\left(\mathrm{p}=2.7 \times 10^{-6}\right)$. These covariates explained $12 \%$ of the total phenotypic variation in T2DM. Subsequently, we performed multipoint linkage analyses to localize the susceptibility loci for T2DM. There was no evidence in favor of significant T2DM linkage. However, as reported in table 3, 2 genetic locations exhibited potential linkage with T2DM. The stronger of the 2 suggestive signals $\left(\mathrm{LOD}=1.8\right.$, nominal $\left.\mathrm{p}=2.1 \times 10^{-3}\right)$ occurred between markers D9S1871 and D9S2169 (9p24.2-p24.1; 8-14 cM), the other suggestive linkage signal (LOD $=1.5$, nominal $\left.\mathrm{p}=4.7 \times 10^{-3}\right)$ involved markers D11S1999-D11S1981, at a region on chromosome $11 \mathrm{p}$ (11p15.3-p15.1; 17-21 cM).

Following these linkage findings and our previous SAFDGS T2DM linkage results, we performed a GWL analysis of T2DM using our combined larger data set $(\mathrm{n}=3,086)$ to examine whether it would yield improved evidence for linkage at any of the genetic locations found to be linked with T2DM in our SAFDGS and/or VAGES data sets. After accounting for the significant ( $p \leq 0.05$ ) covariate effects of age, sex, age ${ }^{2}$, age ${ }^{2} \times$ sex, $\ln \mathrm{BMI}$, and study, which explained $24 \%$ of the total phenotypic variation in T2DM, the heritability of T2DM was estimated to be highly significant $\left(h^{2} \pm S E=0.57 \pm 0.09, p=8.3 \times\right.$ $\left.10^{-15}\right)$. As shown in figures 1 and 2 and table 3 , the GWL of the combined data yielded the strongest, most significant, and improved linkage evidence ( $\mathrm{LOD}=4.3$, nominal $\mathrm{p}=4.3 \times 10^{-6}$, empirical $\mathrm{p}=1.0 \times 10^{-5}$, genome-wide $\left.\mathrm{p}=1.6 \times 10^{-3}\right)$ at the $9 \mathrm{p} 24$ chromosomal region between markers D9S1779 (9p24.3) and D9S1871 (9p24.2). The estimated heritability $( \pm \mathrm{SE})$ due to this susceptibility locus is $0.55 \pm 0.12\left(\mathrm{p}=4.3 \times 10^{-6}\right)$ of the total phenotypic
Farook et al. 


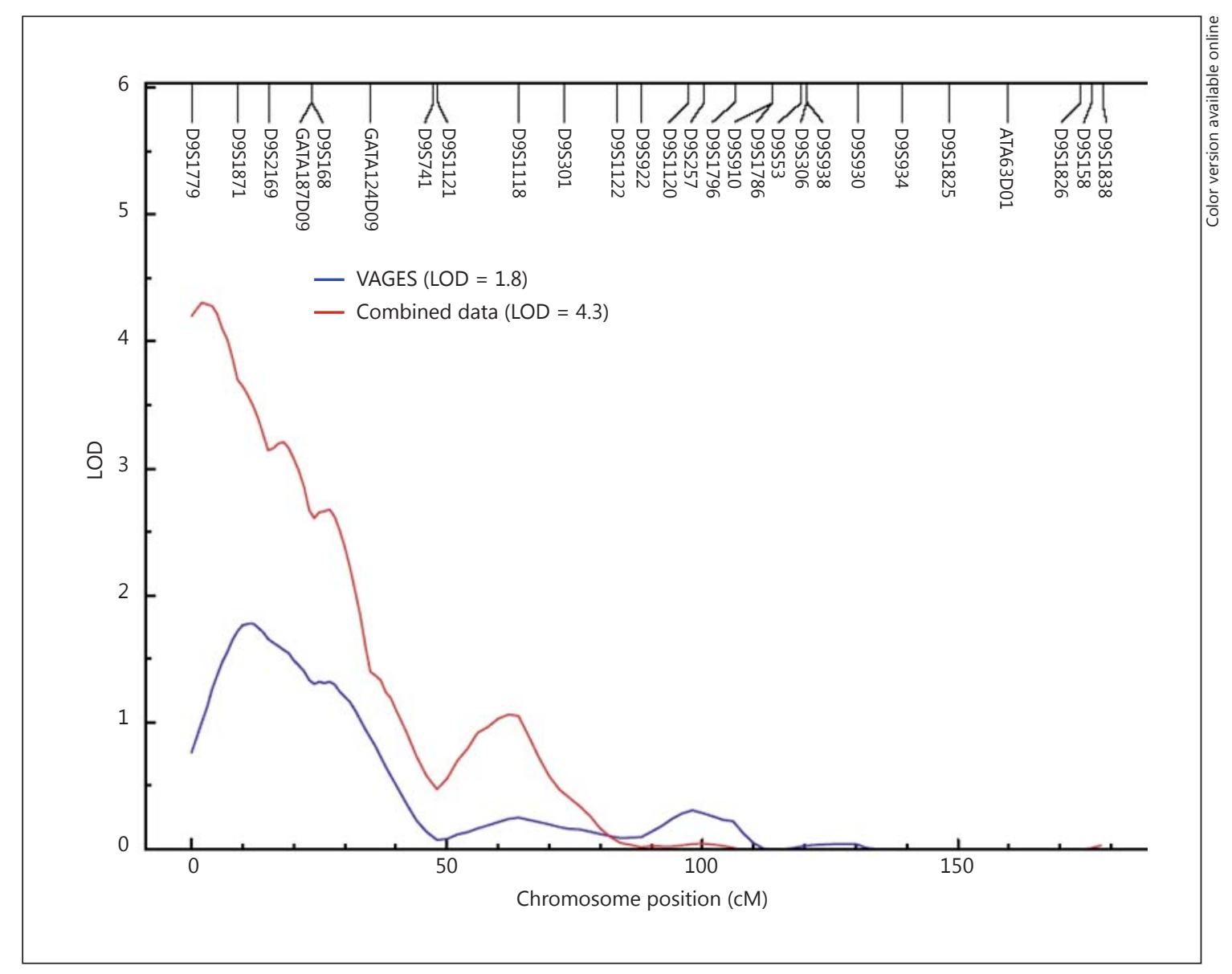

Fig. 2. T2DM linkage profiles on chromosome 9 from the VAGES and the combined data sets.

variation in T2DM after adjusting for the covariate effects. It should be noted that, even after allowing for parameter heterogeneity by obtaining study-specific findings, the LOD score and the location were found to be similar. The observed LOD score of 4.3 with 3 d.f. (i.e., the mixture for the $\chi^{2}$ ) would have a $\mathrm{p}$ value of $4.5 \times 10^{-5}$, which would be equivalent to a LOD score of approximately 3.33. Thus, the linkage finding at the 9 p24 region continues to be significant even after allowing for additional d.f.

As reported in figure 1 and table 3, however, using the combined data, a similar improvement in the linkage signal at the genetic location on chromosome $11 \mathrm{p}$ was not observed $\left(\mathrm{LOD}=1.0\right.$, nominal $\left.\mathrm{p}=1.4 \times 10^{-2}\right)$. In addition to the significant linkage signal on chromosome 9p24, 4 chromosomal regions (i.e., 5p15.31, 5p13.1, 5q13.1-q13.3, and 21q22.11-q22.13) representing 2 chromosomes across the genome exhibited potential evidence for link- age with T2DM (i.e., LOD $\geq 1.2$ ), and the LOD scores ranged from $1.2\left(\right.$ nominal $\left.\mathrm{p}=9.1 \times 10^{-3}\right)$ to 2.0 (nominal $\left.\mathrm{p}=1.1 \times 10^{-3}\right)($ table 3 , fig. 1$)$.

We performed a preliminary T2DM association analysis of the 5,329 SNPs in the 1.5-LOD support interval surrounding the 9p24 linkage signal $[\sim 22 \mathrm{cM}$ or $\sim 10$ $\mathrm{Mb}$ region between markers D9S1779 (9p24.3) and GATA187D09 (9p23)] using data from 2 (i.e., SAFHS and SAFDGS, $\mathrm{n}=\sim 2,000$ ) of the 3 studies used for our linkage analysis (table 1), for which we now have genome-wide genotypic data. In addition to the covariates considered for the GWL analysis, the first 3 principal component-based values (PC1, PC2, and PC3), obtained using a subset of SNPs (that are not in linkage disequilibrium) from the GWAS genotypic data [38], were also considered for the association analysis as covariates to adjust for potential population structure influences. No attempt was made to adjust for multiple testing. The 
Table 4. GWL and association findings on chromosome 9p for T2DM and its related traits

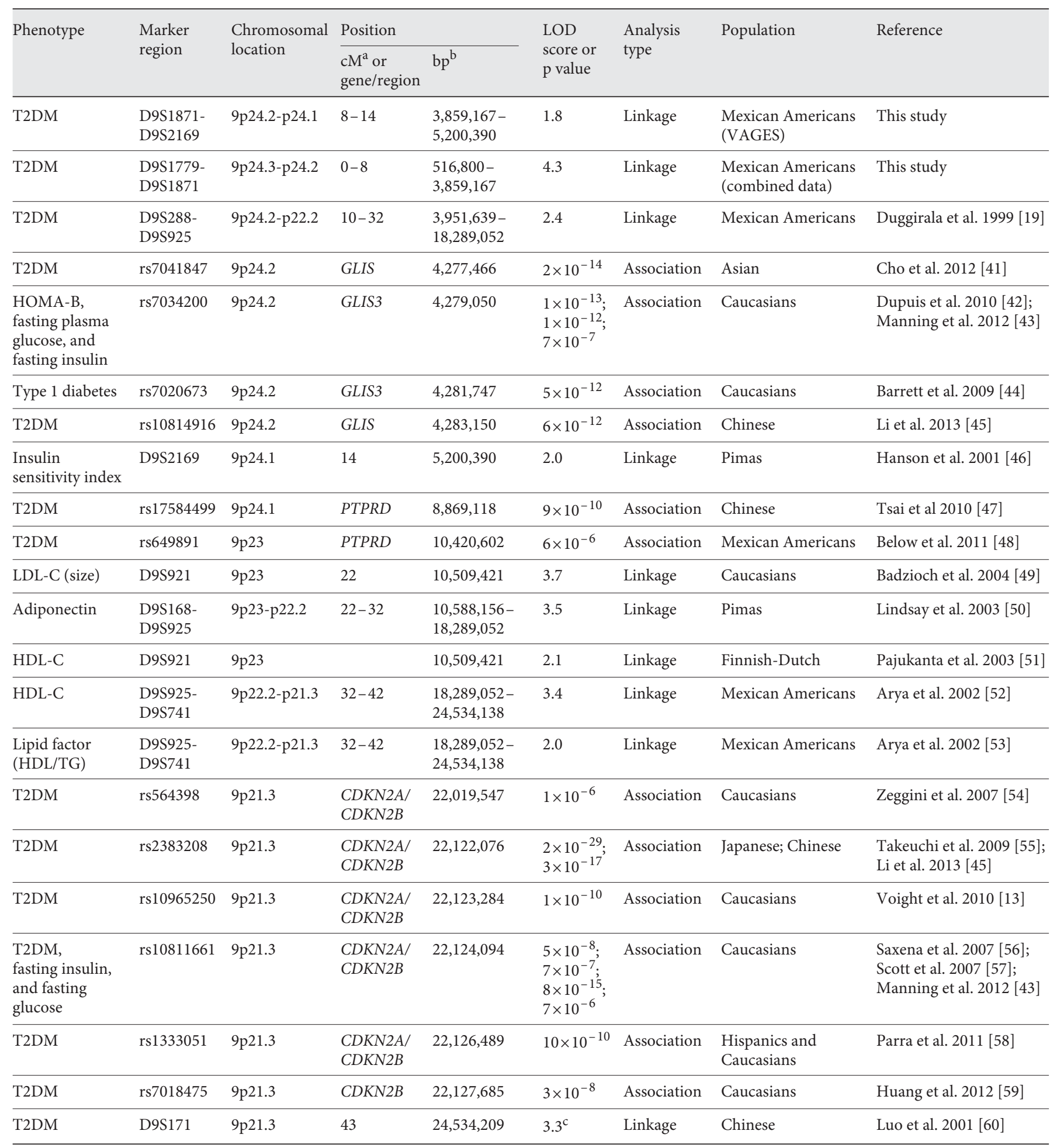

${ }^{a}$ Marshfield distance; ${ }^{b}$ base pair location at the beginning of the marker (NCBI Genome Build 36.3; dbSNP build 130); ${ }^{\mathrm{c}}$ nonparametric linkage score. 
strongest T2DM association was found with rs10976093 $\left(\beta=1.140 ; p=7.3 \times 10^{-5} ; 7.17 \mathrm{Mb}\right)$ near the lysine $(\mathrm{K})$ specific demethylase $4 \mathrm{C}$ (KDM4C) gene. The minor allele A was the risk allele, it was a low-frequency variant $(\mathrm{MAF}=0.009)$. Using the data from nondiabetic individuals only, the strongest associations for fasting glucose $\left(\beta=-0.475 ; \mathrm{p}=1.7 \times 10^{-3} ; \operatorname{MAF}(\mathrm{C})=0.015 ; 3.14\right.$ $\mathrm{Mb})$ and fasting insulin $\left(\beta=0.132 ; \mathrm{p}=6.4 \times 10^{-5}\right.$; $\mathrm{MAF}$ $(A)=0.473 ; 3.77 \mathrm{Mb}$ ) were found with rs1570286 [near the coactivator-associated arginine methyltransferase 1 pseudogene 1 (CARM1P1) gene] and rs7033034 [near the GLIS family zinc finger 3 (GLIS3) gene]. rs1570286 was also nominally associated with T2DM $\left(\mathrm{p}=6.8 \times 10^{-3}\right)$ and fasting insulin $\left(\mathrm{p}=1.3 \times 10^{-2}\right)$.

As reported in table 4, several SNPs in the GLIS3 gene (rs7041847 and rs10814916) and the protein tyrosine phosphatase, receptor type, D (PTPRD) gene (rs17584499 and rs649891), whose locations correspond to the chromosomal region of interest, were reported to be associated with T2DM. None of these markers were found to be associated with T2DM in our data, although suggestive evidence of T2DM association in terms of direction could be seen with rs7041847 (one-sided $\mathrm{p}=0.065$ ) and rs 10814916 (one-sided $p=0.072$ ). However, several other SNPs in these 2 genes exhibited some evidence for association with T2DM, the strongest being rs2027394 in GLIS3 $\left(\mathrm{p}=2.2 \times 10^{-3} ; \operatorname{MAF}(\mathrm{G})=0.395\right)$ and $\mathrm{rs} 10977825$ in PTPRD $\left(\mathrm{p}=2.9 \times 10^{-4}\right.$; MAF $\left.(\mathrm{G})=0.141\right)$.

\section{Discussion}

In this study, we first screened the genome for T2DM susceptibility loci in Mexican Americans using the data from VAGES $(\mathrm{n}=1,122)$ and a GWL approach, which resulted in potential linkage evidence for T2DM at genetic locations on chromosomes 9p24.2-p24.1 and 11p15.3-p15.1. Both of these chromosomal regions have previously been implicated as influencing T2DM-related traits by various GWL studies including our own $[19,28,39,40$, see also table 4 for additional studies related to chromosome 9]. Recently, certain variants/genes [PTPRD and GLIS3 on 9p24.3-p23 and the UDP-N-acetyl-alpha-D-galactosamine:polypeptide $\mathrm{N}$-acetylgalactosaminyltransferase 18 (GALNT18) gene/ LOC729013 and the potassium inwardly rectifying channel, subfamily J, member 11 (KCNJ11) gene on 11p15.3-p15.1] have been localized as T2DM susceptibility loci in these chromosomal regions by GWASs [16, 25, 61].

Following these observations, we performed a GWL of T2DM using an enlarged data set consisting of individu-

Linkage of T2DM on Chromosome 9p24

in Mexican Americans als from VAGES, SAFHS, and SAFDGS. We found the significant and increased evidence for linkage of T2DM at the 9p24.3-p24.2 chromosomal region $(\mathrm{LOD}=4.3$, empirical $\mathrm{p}=1.0 \times 10^{-5}$, genome-wide $\mathrm{p}=1.6 \times 10^{-3}$, 0-8 cM). As reported in tables 3 and 4, the peak LOD score on chromosome 9p24.2-p24.1 in the VAGES data ( $\mathrm{LOD}=1.8$ ) occurred at $8-14 \mathrm{cM}$. Previously, the SAFDGS (baseline) data exhibited suggestive linkage evidence $(\mathrm{LOD}=2.4)$ at $10-32 \mathrm{cM}$ on 9p24.2-p22.2. It should be noted that the current SAFDGS genotypic data were generated by CIDR, using genetic markers which are different from those used at baseline, and that the BMI was not used as a covariate in the baseline data analysis. However, the combined data analysis greatly improved the evidence for T2DM linkage as noted above.

Although the linkage evidence on 11p15.3-p15.1 was attenuated compared to the VAGES finding, new potential evidence for T2DM linkage in our data was found at 3 different locations on chromosome 5 (i.e., 5p15.31, 5p13.1, and 5q13.1-q13.3) and at the 21q22.11-q22.13 chromosomal region. Several previous studies found some evidence for linkage of T2DM-related traits at these regions [62-64]. Interestingly, the chromosomal regions $5 q 13.3$ and 21q22.11 exhibit a close correspondence with recent T2DM GWAS findings involving the zinc finger, BED-type containing 3 (ZBED3) gene region (5q13.3) and the hormonally up-regulated Neu-associated kinase (HUNK) gene region (21q22.11) [13,65].

The major linkage finding of our study, however, is the T2DM susceptibility locus on chromosome 9p24, which explains about $55 \%$ of the total phenotypic variation in T2DM after adjusting for the covariate effects. It is plausible that the observed linkage signal refers to potential T2DM functional variants, both rare and common, in a genetic location representing one or more genes on chromosome 9p24. The 1.5-LOD support interval on the centromeric side of the linkage peak (i.e., combined data) is flanked by the marker GATA187D09 (9p23, 22 cM, 10 $\mathrm{Mb})$. Aside from the information from GWL studies of T2DM-related traits on chromosome 9p (table 4), as noted earlier, some recent GWASs have localized variants/genes within the $10-\mathrm{Mb}$ chromosomal region from $\mathrm{p}$-ter that influence susceptibility to T2DM or its related traits (table 4).

One of the most interesting genes in this region that has been reported to play a key role in the pancreatic $\beta$ cell development and insulin gene expression is GLIS3 (9p24.2, 3.8-4.3 Mb). Two SNPs in the intronic region of GLIS3, namely rs7041847 and rs7034200, showed significant associations with T2DM in Asians and with HOMA-B levels, fasting plasma glucose and fasting insulin in Caucasians 
[41-43]. Another intronic polymorphism (rs7020673) in the same gene was found to be associated with T1DM in Caucasians [44]. Tsai et al. [47], using data from a Chinese population, reported that a variant $\mathrm{rs} 17584499$ in the intron region of the PTPRD gene (9p24.3-p23, 8.3-10.6 Mb) was significantly associated with T2DM. Interestingly, rs649891 (9p23), yet another intronic SNP in the same gene, showed an association with T2DM in Mexican Americans [48]. It is important to note that GWAS-identified variants in the regions of the cyclin-dependent kinase inhibitor $2 \mathrm{~A} / 2 \mathrm{~B}$ genes $(C D K N 2 \mathrm{~A} / C D K N 2 B)$ are located at approximately $22.1 \mathrm{Mb}$ from p-ter, and that this chromosomal region is approximately $12 \mathrm{Mb}$ away from the marker GATA187D09 region that flanks the 1.5-LOD support interval on the centromeric side in our data. It is worth noting that our previous HDL cholesterol linkage signal within the approximately $18.3-24.5-\mathrm{Mb}$ chromosomal region strongly overlaps with the CDKN2A/ CDKN2B gene regions (i.e., $22.1 \mathrm{Mb}$, table 4).

We performed a preliminary T2DM association analysis within the 1.5-LOD support interval on chromosome 9p24.3-p23, using a subset of data (SAFHS and SAFDGS) that contributed to the 9p24 linkage signal. Of the available SNPs in this critical region in our data, the strongest T2DM association involved a low-frequency variant (rs10976093, intergenic, 7.1 Mb, MAF $=0.009)$ near the KDM4C gene. Markers rs7041847 and rs10814916 (GLIS3), and rs17584499 and rs649891 (PTPRD), which were part of the analysis, failed to exhibit association with T2DM, although suggestive evidence of association with T2DM in terms of direction was found with rs7041847 and rs10814916. However, several other SNPs in these 2 genes exhibited some evidence of association with T2DM, including rs2027394 in GLIS3 and rs10977825 in PTPRD. In nondiabetic individuals, marker rs7033034 (intergenic, $3.8 \mathrm{Mb}$ ) near the GLIS3 gene was strongly associated with fasting insulin, and marker rs1570286 (intergenic, $3.1 \mathrm{Mb}$ ) near the CARM1P1 gene was strongly associated with fasting glucose, which was also nominally associated with T2DM and fasting insulin.

The above observations highlight the relative significance of the GLIS3 and PTPRD genetic regions as well as other regions related to the KDM4C and CARM1P1 genes in the $9 \mathrm{p}$-linked region, as they relate to a potential T2DM risk. Given the attention to the nature of these associations and the magnitude of the linkage signal, a thorough search of the 9p chromosomal region for rare variants, in addition to the common variants that may correspond to the T2DM linkage signal, appears to be a promising approach. As reported in table 4, several metabolic syndrome-related traits are linked or associated with the 9p chromosomal region besides T2DM. It is possible that the 9p chromosomal region could harbor genes that may have pleiotropic influences on metabolic syndrome-related traits. However, we have recently reported linkage findings of metabolic syndrome (as defined by the NCEP/ATPIII criteria) using our SAFDGS data, and there was no evidence for linkage of metabolic syndrome on chromosome 9 [66].

In summary, this study has identified the strongest linkage evidence for T2DM at 9p24 in Mexican Americans. Although the independent T2DM linkage evidence based on VAGES and SAFDGS data sets would be considered potential or suggestive, the large combined family data set used in this study yielded improved and significant evidence for a linkage of T2DM on chromosome 9 p24. In addition, some recent GWASs have also unveiled certain variants/genes associated with T2DM and related traits in this chromosomal region. Importantly, we have found preliminary evidence for an association of T2DM and its related traits with sequence variants (both common and low-frequency) representing distinct genetic locations within the $9 \mathrm{p}$ chromosomal region of interest. In comparison to GWL studies, the chromosomal regions of interest identified by GWASs usually involve small confidence interval regions ( $500 \mathrm{~kb}$ to $1 \mathrm{Mb}$ ). Collectively, these studies together with our current findings provide strong evidence for the presence of susceptibility loci for T2DM on chromosome 9p24, while in turn making the case for the performance of high throughput sequencing of this linked chromosomal region to ultimately capture the causal variants, including the rare ones, responsible for the original linkage/association signals. In fact, large family-based studies like ours have a high likelihood of detecting the rare or very rare variants, given that multiple individuals in large families can be associated with such sequence variants.

\section{Acknowledgments}

We thank Marcel J. Fourcaudot and Lenore M. Rodriguez for their excellent technical assistance. We thank our nurses, James King, John Kincaid, Rose Kaminski-Graham, and Norma Diaz, for their excellent care of the participants throughout the study. This work was supported by a Veterans Administration Epidemiologic grant to R.A.D. This study was also supported in part by grants from the National Institutes of Health (DK42273, DK47482, DK53889, DK70746, HD41111, and MH59490). We thank the CIDR for providing genome scans using the VAGES and SAFDGS data sets, respectively. We thank the participants of VAGES, SAFHS, and SAFDGS, and are grateful for their generous partaking and cooperation.
44

Hum Hered 2013;76:36-46 DOI: $10.1159 / 000354849$
Farook et al. 


\section{References}

1 DeFronzo RA: Pathogenesis of type 2 diabetes: metabolic and molecular implications for identifying diabetes genes. Diabetes Rev 1997; 5:177-269.

$\checkmark 2$ DeFronzo RA: Banting Lecture. From the triumvirate to the ominous octet: a new paradigm for the treatment of type 2 diabetes mellitus. Diabetes 2009;58:773-795.

$>3$ Reaven GM: Pathophysiology of insulin resistance in human disease. Physiol Rev 1995;75: 473-486.

4 Centers for Disease Control and Prevention: Chronic Disease Prevention: Preventing Diabetes and Its Complications. Atlanta, Department of Health and Human Services, Centers for Disease Control and Prevention, 2008.

$>5$ Stern MP, Gaskill SP, Hazuda HP, Gardner LI, Haffner SM: Does obesity explain excess prevalence of diabetes among Mexican Americans? Results of the San Antonio Heart Study. Diabetologia 1983;24:272-277.

6 Harlan LC, Harlan WR, Landis JR, Goldstein NG: Factors associated with glucose tolerance in adults in the United States. Am J Epidemiol 1987;126:674-684.

7 Barnett AH, Eff C, Leslie RDG, Pyke DA: Diabetes in identical twins: a study of 200 pairs. Diabetologia 1981;20:87-93.

$>8$ Klein BE, Klein R, Moss SE, Cruickshanks KJ: Parental history of diabetes in a population-based study. Diabetes Care 1996;19: 827-830.

$>9$ Poulsen P, Kyvik KO, Vaag A, Beck-Nielsen $\mathrm{H}$ : Heritability of type II (non-insulin-dependent) diabetes mellitus and abnormal glucose tolerance - a population-based twin study. Diabetologia 1999;42:139-145

10 Guan W, Pluzhnikov A, Cox NJ, Boehnke M; International Type 2 Diabetes Linkage Analysis Consortium: Meta-analysis of 23 type 2 diabetes linkage studies from the International Type 2 Diabetes Linkage Analysis Consortium. Hum Hered 2008;66:35-49.

-11 Prokopenko I, McCarthy MI, Lindgren CM: Type 2 diabetes: new genes, new understanding. Trends Genet 2008;24:613-621.

$\checkmark 12$ Sladek R, Rocheleau G, Rung J, Dina C, Shen L, Serre D, Boutin P, Vincent D, Belisle A, Hadjadj S, Balkau B, Heude B, Charpentier G, Hudson TJ, Montpetit A, Pshezhetsky AV, Prentki M, Posner BI, Balding DJ, Meyre D, Polychronakos C, Froguel P: A genome-wide association study identifies novel risk loci for type 2 diabetes. Nature 2007;445:881-885.

13 Voight BF, Scott LJ, Steinthorsdottir V, Morris AP, Dina C, et al: Twelve type 2 diabetes susceptibility loci identified through largescale association analysis. Nat Genet 2010;42: 579-589.

14 Scott RA, Lagou V, Welch RP, Wheeler E, Montasser ME, et al: Large-scale association analyses identify new loci influencing glycemic traits and provide insight into the underlying biological pathways. Nat Genet 2012;44: 991-1005.
15 Drong AW, Lindgren CM, McCarthy MI: The genetic and epigenetic basis of type 2 diabetes and obesity. Clin Pharmacol Ther 2012;92: 707-715.

16 National Human Genome Research Institute http://www.genome.gov/gwastudies/ (accessed on September 9, 2013).

17 Reynisdottir I, Thorleifsson G, Benediktsson R, Sigurdsson G, Emilsson V, et al: Localization of a susceptibility gene for type 2 diabetes to chromosome 5q34-q35.2. Am J Hum Genet 2003;73:323-335.

18 Grant SF, Thorleifsson G, Reynisdottir I, Benediktsson R, Manolescu A, et al: Variant of transcription factor 7-like 2 (TCF7L2) gene confers risk of type 2 diabetes. Nat Genet 2006;38:320-323.

19 Duggirala R, Blangero J, Almasy L, Dyer TD, Williams KL, Leach RJ, O'Connell P, Stern MP: Linkage of type 2 diabetes mellitus and of age at onset to a genetic location on chromosome 10q in Mexican Americans. Am J Hum Genet 1999;64:1127-1140.

20 Manolio TA, Collins FS, Cox NJ, Goldstein DB, Hindorff LA, et al: Finding the missing heritability of complex diseases. Nature 2009; 461:747-753.

21 Dickson SP, Wang K, Krantz I, Hakonarson H, Goldstein DB: Rare variants create synthetic genome-wide associations. PLoS 2010; 8:e1000294.

22 Gibson G: Rare and common variants: twenty arguments. Nat Rev Genet 2012;13:135-145.

23 Rosenberg NA, Huang L, Jewett EM, Szpiech ZA, Jankovic I, Boehnke M: Genome-wide association studies in diverse populations. Nat Rev Genet 2010;11:356-366.

24 Saxena R, Elbers CC, Guo Y, Peter I, Gaunt $\mathrm{TR}$, et al: Large-scale gene-centric meta-analysis across 39 studies identifies type 2 diabetes loci. Am J Hum Genet 2012;90:410-425.

25 Sanghera DK, Blackett PR: Type 2 diabetes genetics: beyond GWAS. J Diabetes Metab 2012; 3:6948.

26 Ng MC, Saxena R, Li J, Palmer ND, Dimitrov L, Xu J, Rasmussen-Torvik LJ, Zmuda JM, Siscovick DS, Patel SR, Crook ED, Sims M, Chen YD, Bertoni AG, Li M, Grant SF, Dupuis J, Meigs JB, Psaty BM, Pankow JS, Langefeld CD, Freedman BI, Rotter JI, Wilson JG, Bowden DW: Transferability and fine mapping of type 2 diabetes loci in African Americans: the Candidate Gene Association Resource Plus Study. Diabetes 2013;62:965-976.

27 Texas Biomedical Research Institute: http:// www.txbiomed.org/solar (accessed on September 9, 2013).

28 Hunt KJ, Lehman DM, Arya R, Fowler S, Leach RJ, Goring HH, Almasy L, Blangero J, Dyer TD, Duggirala R, Stern MP: Genomewide linkage analyses of type 2 diabetes in Mexican-Americans: the San Antonio Family Diabetes/Gallbladder Study. Diabetes 2005; 54:2655-2662.
29 Coletta DK, Schneider J, Hu SL, Dyer TD, Puppala S, Farook VS, Arya R, Lehman DM, Blangero J, DeFronzo RA, Duggirala R, Jenkinson CP: Genome-wide linkage scan for genes influencing plasma triglyceride levels in the Veterans Administration Genetic Epidemiology Study. Diabetes 2009;58:279284.

30 World Health Organization: Definition, diagnosis and classification of diabetes mellitus and its complications: report of a WHO consultation. Part I. Diagnosis and classification of diabetes mellitus. Geneva, World Health Organization, 1999.

31 Almasy L, Blangero J: Multipoint quantitative-trait linkage analysis in general pedigrees. Am J Hum Genet 1998;62:1198-1211.

32 Duggirala R, Williams JT, Williams-Blangero $\mathrm{S}$, Blangero J: A variance component approach to dichotomous trait linkage analysis using a threshold model. Genet Epidemiol 1997;14:987-992.

33 Arya R, Demerath E, Jenkinson CP, Göring $\mathrm{HH}$, Puppala S, Farook V, Fowler S, Schneider J, Granato R, Resendez RG, Dyer TD, Cole SA, Almasy L, Comuzzie AG, Siervogel RM, Bradshaw B, DeFronzo RA, MacCluer J, Stern MP, Towne B, Blangero J, Duggirala R: A quantitative trait locus (QTL) on chromosome $6 \mathrm{q}$ influences birth weight in two independent family studies. Hum Mol Genet 2006;15:1569-1579.

34 Mitchell BD, Kammerer CM, Blangero J, Mahaney MC, Rainwater DL, et al: Genetic and environmental contributions to cardiovascular risk factors in Mexican-Americans. The San Antonio Family Heart Study. Circulation 1996;94:2159-2170.

35 Puppala S, Dodd GD, Fowler S, Arya R, Schneider J, Farook VS, Granato R, Dyer TD, Almasy L, Jenkinson CP, Diehl AK, Stern MP, Blangero J, Duggirala R: A genomewide search finds major susceptibility loci for gallbladder disease on chromosome 1 in Mexican Americans. Am J Hum Genet 2006;78:377-392.

36 Feingold E, Brown PO, Siegmund D: Gaussian models for genetic linkage analysis using complete high-resolution maps of identity by descent. Am J Hum Genet 1993;53:234251 .

37 Dupuis J, Siegmund D: Statistical methods for mapping quantitative trait loci from a dense set of markers. Genetics 1999;151:373386.

38 Rubicz R, Yolken R, Drigalenko E, Carless MA, Dyer TD, Bauman L, Melton PE, Kent JW Jr, Harley JB, Curran JE, Johnson MP, Cole SA, Almasy L, Moses EK, Dhurandhar NV, Kraig E, Blangero J, Leach CT, Göring $\mathrm{HH}$ : A genome-wide integrative genomic study localizes genetic factors influencing antibodies against Epstein-Barr virus nuclear antigen 1 (EBNA-1). PLoS Genet 2013; 9:e1003147. 
-39 Stern MP, Duggirala R, Mitchell BD, Reinhart LJ, Shivakumar S, Shipman PA, Uresandi OC, Benavides E, Blangero J, O'Connell P: Evidence for linkage of regions on chromosomes 6 and 11 to plasma glucose concentrations in Mexican Americans. Genome Res 1996;6: 724-734.

-40 Vionnet N, Hani EH, Dupont S, Gallina S, Francke S, Dotte S, De Matos F, Durand E, Leprêtre F, Lecoeur C, Gallina P, Zekiri L, Dina C, Froguel P: Genomewide search for type 2 diabetes-susceptibility genes in French whites: evidence for a novel susceptibility locus for early-onset diabetes on chromosome $3 q 27-q$ ter and independent replication of a type 2-diabetes locus on chromosome 1q21q24. Am J Hum Genet 2000;67:1470-1480.

-41 Cho YS, Chen CH, Hu C, Long J, Ong RT, et al: Meta-analysis of genome-wide association studies identifies eight new loci for type 2 diabetes in east Asians. Nat Genet 2012;44:67-72.

-42 Dupuis J, Langenberg C, Prokopenko I, Saxena R, Soranzo N, et al: New genetic loci implicated in fasting glucose homeostasis and their impact on type 2 diabetes risk. Nat Genet 2010;42:105-116.

-43 Manning AK, Hivert MF, Scott RA, Grimsby JL, Bouatia-Naji N, et al: A genome-wide approach accounting for body mass index identifies genetic variants influencing fasting glycemic traits and insulin resistance. Nat Genet 2012;44:659-669.

-44 Barrett JC, Clayton DG, Concannon P, Akolkar B, Cooper JD, Erlich HA, Julier C, Morahan G, Nerup J, Nierras C, Plagnol V, Pociot F, Schuilenburg H, Smyth DJ, Stevens H, Todd JA, Walker NM, Rich SS; Type 1 Diabetes Genetics Consortium: Genome-wide association study and meta-analysis find that over 40 loci affect risk of type 1 diabetes. Nat Genet 2009;41:703-707.

-45 Li H, Gan W, Lu L, Dong X, Han X, Hu C, Yang Z, Sun L, Bao W, Li P, He M, Sun L, Wang Y, Zhu J, Ning Q, Tang Y, Zhang R, Wen J, Wang D, Zhu X, Guo K, Zuo X, Guo $X$, Yang H, Zhou X; DIAGRAM Consortium; AGEN-T2D Consortium; Zhang X, Qi L, Loos RJ, Hu FB, Wu T, Liu Y, Liu L, Yang Z, Hu R, Jia W, Ji L, Li Y, Lin X: A genome-wide association study identifies GRK5 and RASGRP1 as type 2 diabetes loci in Chinese Hans. Diabetes 2013;62:291-298.

- 46 Hanson RL, Imperatore G, Narayan KM, Roumain J, Fagot-Campagna A, Pettitt DJ, Bennett PH, Knowler WC: Family and genetic studies of indices of insulin sensitivity and insulin secretion in Pima Indians. Diabetes Metab Res Rev 2001;17:296-303.

$\checkmark 47$ Tsai FJ, Yang CF, Chen CC, Chuang LM, Lu $\mathrm{CH}$, Chang CT, Wang TY, Chen RH, Shiu CF, Liu YM, Chang CC, Chen P, Chen CH, Fann CS, Chen YT, Wu JY: A genome-wide association study identifies susceptibility variants for type 2 diabetes in Han Chinese. PLoS Genet 2010;6:e1000847.
48 Below JE, Gamazon ER, Morrison JV, Konkashbaev A, Pluzhnikov A, McKeigue PM, Parra EJ, Elbein SC, Hallman DM, Nicolae DL, Bell GI, Cruz M, Cox NJ, Hanis CL: Genome-wide association and meta-analysis in populations from Starr County, Texas, and Mexico City identify type 2 diabetes susceptibility loci and enrichment for expression quantitative trait loci in top signals. Diabetologia 2011;54:2047-2055.

49 Badzioch MD, Igo RP Jr, Gagnon F, Brunzell JD, Krauss RM, Motulsky AG, Wijsman EM, Jarvik GP: Low-density lipoprotein particle size loci in familial combined hyperlipidemia: evidence for multiple loci from a genome scan. Arterioscler Thromb Vasc Biol 2004;24: 1942-1950.

50 Lindsay RS, Funahashi T, Krakoff J, Matsuzawa Y, Tanaka S, Kobes S, Bennett PH, Tataranni PA, Knowler WC, Hanson RL: Genome-wide linkage analysis of serum adiponectin in the Pima Indian population. Diabetes 2003;52:2419-2425.

51 Pajukanta P, Allayee H, Krass KL, Kuraishy A, Soro A, Lilja HE, Mar R, Taskinen MR, Nuotio I, Laakso M, Rotter JI, de Bruin TW, Cantor RM, Lusis AJ, Peltonen L: Combined analysis of genome scans of Dutch and Finnish families reveals a susceptibility locus for high-density lipoprotein cholesterol on chromosome 16q. Am J Hum Genet 2003;72:903-917.

-52 Arya R, Duggirala R, Almasy L, Rainwater DL, Mahaney MC, Cole S, Dyer TD, Williams K, Leach RJ, Hixson JE, MacCluer JW, O'Connell P, Stern MP, Blangero J: Linkage of high-density lipoprotein-cholesterol concentrations to a locus on chromosome 9p in Mexican Americans. Nat Genet 2002;30:102-105.

53 Arya R, Blangero J, Williams K, Almasy L, Dyer TD, Leach RJ, O'Connell P, Stern MP, Duggirala R: Factors of insulin resistance syndrome-related phenotypes are linked to genetic locations on chromosomes 6 and 7 in nondiabetic Mexican-Americans. Diabetes 2002;51:841-847.

54 Zeggini E, Weedon MN, Lindgren CM, Frayling TM, Elliott KS, et al: Replication of genome-wide association signals in UK samples reveals risk loci for type 2 diabetes. Science 2007;316:1336-1341.

55 Takeuchi F, Serizawa M, Yamamoto K, Fujisawa T, Nakashima E, Ohnaka K, Ikegami H, Sugiyama T, Katsuya T, Miyagishi M, Nakashima N, Nawata H, Nakamura J, Kono S, Takayanagi R, Kato N: Confirmation of multiple risk loci and genetic impacts by a genome-wide association study of type 2 diabetes in the Japanese population. Diabetes 2009; 58:1690-1699.

56 Saxena R, Voight BF, Lyssenko V, Burtt NP, de Bakker PI, et al: Genome-wide association analysis identifies loci for type 2 diabetes and triglyceride levels. Science 2007;316:1331-1336.
57 Scott LJ, Mohlke KL, Bonnycastle LL, Willer $\mathrm{CJ}$, Li Y, et al: A genome-wide association study of type 2 diabetes in Finns detects multiple susceptibility variants. Science 2007;316: 1341-1345.

58 Parra EJ, Below JE, Krithika S, Valladares A, Barta JL, Cox NJ, Hanis CL, Wacher N, Garcia-Mena J, Hu P, Shriver MD; Diabetes Genetics Replication and Meta-analysis (DIAGRAM) Consortium; Kumate J, McKeigue PM, Escobedo J, Cruz M: Genome-wide association study of type 2 diabetes in a sample from Mexico City and a meta-analysis of a Mexican-American sample from Starr County, Texas. Diabetologia 2011;54:2038-2046.

59 Huang J, Ellinghaus D, Franke A, Howie B, Li Y: 1000 Genomes-based imputation identifies novel and refined associations for the Wellcome Trust Case Control Consortium phase 1 Data. Eur J Hum Genet 2012;20:801-805.

60 Luo TH, Zhao Y, Li G, Yuan WT, Zhao JJ, Chen JL, Huang W, Luo M: A genome-wide search for type II diabetes susceptibility genes in Chinese Hans. Diabetologia 2001;44:501506.

61 Palmer ND, McDonough CW, Hicks PJ, Roh $\mathrm{BH}$, Wing MR, et al: A genome-wide association search for type 2 diabetes genes in African Americans. PLoS One 2012;7:e29202.

62 Lindsay RS, Kobes S, Knowler WC, Bennett PH, Hanson RL: Genome-wide linkage analysis assessing parent-of-origin effects in the inheritance of type 2 diabetes and BMI in Pima Indians. Diabetes 2003;50:2850-2857.

63 Frayling TM, Wiltshire S, Hitman GA, Walker M, Levy JC, Sampson M, Groves CJ, Menzel S, McCarthy MI, Hattersley AT: Young-onset type 2 diabetes families are the major contributors to genetic loci in the Diabetes UK Warren 2 genome scan and identify putative novel loci on chromosomes 8q21,21q22, and 22q11. Diabetes 2003;52:1857-1863.

64 Iwasaki N, Cox NJ, Wang YQ, Schwarz PE, Bell GI, Honda M, Imura M, Ogata M, Saito M, Kamatani N, Iwamoto Y: Mapping genes influencing type 2 diabetes risk and BMI in Japanese subjects. Diabetes 2003;52:209-213.

65 Sim X, Ong RT, Suo C, Tay WT, Liu J, Ng DP, Boehnke M, Chia KS, Wong TY, Seielstad M, Teo YY, Tai ES: Transferability of type 2 diabetes implicated loci in multi-ethnic cohorts from Southeast Asia. PLoS Genet 2011; 7:e1001363.

66 Farook VS, Puppala S, Schneider J, Fowler SP, Chittoor G, Dyer TD, Allayee H, Cole SA, Arya R, Black MH, Curran JE, Almasy L, Buchanan TA, Jenkinson CP, Lehman DM, Watanabe RM, Blangero J, Duggirala R: Metabolic syndrome is linked to chromosome $7 \mathrm{q} 21$ and associated with genetic variants in CD36 and GNAT3 in Mexican Americans. Obesity (Silver Spring) 2012;20:20832092. 


\section{Erratum}

In the article by Farook VS et al., entitled 'Linkage of type 2 diabetes on chromosome 9p24 in Mexican Americans: additional evidence from the Veterans Administration Genetic Epidemiology Study (VAGES)' [Hum Hered 2013;76:36-46, DOI:10.1159/000354849], the name of the institute has changed from 'Southwest Foundation for Biomedical Research, San Antonio, Tex.' to 'Texas Biomedical Research Institute, San Antonio, Tex.'. 